welcher Beziehung sie zu den Nervenfädchen stehen, welche man im Kern oder im Kernkörperchen endigen lässt, oder ob sie nicht die Ausgangs- oder Endpunkte noch feinerer Strukturverhältnisse sind.

Die innere Kernschale - der helle Hof im Querschnitt mag, wie angegeben, gewöhnlich aus einer strukturlosen Masse bestehen; da und dort aber schien er mir einen Hohlraum darzustellen. Hierüber werde ich in meiner nächsten Arbeit 1) Einiges $\mathrm{zu}$ berichten haben.

Hier nur noch Folgendes: wenn zwei Kernkörperchen in einem Kern liegen, so ist jedes derselben von einem hellen Hof und von einem Körnchenkreis umgeben ${ }^{2}$ ). Man sieht nun in Bildern, wie deren eines in Fig. 4 dargestellt ist, dass die zwei Höfe und Kreise der neuentstandenen Kernkörperchen aus dem einen des Mutterkernkörperchens hervorgegangen sind durch. Abschnürung. Die Abschnürung ist aber nicht zugleich eine Halbirung, sondern. der Kreis des einen der neuen Kernkörperchen schnürt sich als viel kleinerer Theil - nach Art einer Ausbuchtung, einer Sprosse von dem ursprünglich vorhandenen Mutterkreis $a b$, um sich erst später zu erweitern, so dass das eine der neuen Kernkörperchen mit seinem Zubehör dem anderen gegenüber wie ein Stiefkind erscheint.

Schliesslich noch die Bemerkung, dass ich den Körnchenkreis auch im Keimbläschen junger Eier gesehen zu haben glaube.

1) Untersuchungen über die Eier einiger Reptilien.

2) Vergl. die Schnautze des Maulwurfs etc., l. c.

\title{
Berichtigungen zu Bd. 7 dieses Archivs.
}

S. 344 Zeile 5 statt und lies $v$ on.

- $351-18-\eta(2)$ lies $\zeta$.

- $353-24-1$ gramm lies $10 \mathrm{gramm}$.

- 356 Anm. Zeile 3 statt pag. 361 lies pag. 350 .

- 357 Zeile 12 statt pag. 12 bis pag. 62 lies pag. 12 , - pag. 62.

- 358 - 1 ebenso pag. $13,-$ p. 68 .

- 362 - 16 statt deren lies daran.

- $362-30$ - eingebildet lies einmal gebildet. 